\title{
Digital Natives Facebook readiness For online Entrepreneurial Learning in Small Transition Economies
}

\author{
Oliana Sula \\ Estonian Business School, Tallinn, Estonia \\ Lauteri.3 14110 Tallinn, Estonia \\ olianasula@gmail.com
}

\begin{abstract}
Young students in small transition economies are digital natives and active users of online social networks. Entrepreneurial learning and entrepreneurial opportunities may arise from their activity in online social networks. In order to take advantage from the entrepreneurial education potential of online social networks, Facebook readiness must be determined. Facebook is the most widespread online social network globally even there are a lot of recent controversies about how young people use it and how the limits and the impacts of its usage can be defined. The aim of this paper is to analyze different constructs and their respective structure which determine Facebook readiness for entrepreneurial purposes in a small open economy such as Albania. This study employs mixed methods approach. Quantitative data from were collected from a questionnaire distributed to Albanian students and analyzed with Exploratory Factor Analysis technique where structure of seven constructs of Facebook readiness for entrepreneurial purposes were determined. Qualitative data are collected from focus groups and interviews and they are used to analyze two other implications of online social networking readiness such as support from online mentors and online entrepreneurial orientation. Focus groups were arranged in Tallinn and Helsinki with Estonian, Finish and international Erasmus + students served to explore further on the challenges of Facebook readiness for entrepreneurial learning compared to other online social networks and focusing on the online networking mentoring dimension. 12 semi-structured interviews were realized with more experienced Albanian and Estonian young entrepreneurs in order to explore entrepreneurial learning orientation.
\end{abstract}

Keywords: Facebook Readiness, Online Entrepreneurial Learning, Online Mentoring, Online Entrepreneurial Learning Strategies

Received: 3 May 2018, Revised 20 June 2018. Accepted 29 June 2018

DOI: $10.6025 /$ jet/2018/9/3/82-96

C)2018 DLINE. All rights reserved

\section{Introduction}

Facebook born within the academic context with 2.23 billion users in 2018(Statistica, 2018) is the most used online social network globally. "Being in Facebook" is not any more exceptional but it is rather more something very common and conventional even in small transition economies in South Eastern Europe such Albania. Networking in Facebook is an opportunity for young students to increase their offline and online participation in different fields of interest.

The distinctive potential of using Facebook for educational purposes has been affirmed from different scholars worldwide

\begin{tabular}{lllll}
\hline 82 & Journal of E - Technology Volume 9 & Number 3 August 2018 \\
\hline
\end{tabular}


(Barczyk\& Duncan, 2013;Joosten, 2012) putting emphasis in the in knowledge sharing process that implies. Entrepreneurial education has been part of the curricula in Business Degree programs in Albania after the year 2000. The country is a small country with one of the youngest populations in Europe, the tendency of choosing business orientated academic degrees has increased especially after the fall of communism.

Public policies in Albania tend to focus more and more in incentivizing towards entrepreneurship especially for young students enrolled in Business Degree programs in higher education institutions.

Integrating online social network dimension to entrepreneurial learning can be beneficial for students (Welsh \&Dragusin, 2013) because the future of internet assumes that even though young students are born digital that should be ready to embrace digital transformation.

Facebook presence overcomes geographical boarders and more than just entertainment online social networks when contacts are more than just contacts but friends it can represent an opportunity for entrepreneurial learning in a global perspective. In Albania there are currently 1.4 million Facebook users (Statcounter, 2018). Nevertheless young students in Albania need to be prepared for Facebook entrepreneurial learning.

The purpose of this paper is to explore how readiness to use Facebook for young student entrepreneurial learning can be developed in the context of a small open economy in Europe such as Albania having an emphasis as well as well on the dimensions on further support from online mentors and online entrepreneurial learning orientation emphasis. The methodological approach of this study is mixed methods. Quantitative data was collected from a questionnaire distributed to young Albanian students in Business Degree at the University "Aleksander Mosiu” Durres and at the University of Tirana during the Spring semester 2018. Qualitative data was collected from focus groups realized during the end of academic year 2018 at Estonian Business School in Helsinki and Tallinn with Estonian, Finnish and international students from Erasmus + program with the aim to further analyze the constructs of the study and compare with another cultural context. The second part of qualitative data that focused more in exploring online entrepreneurial learning orientation was collected through semi-structured interviews realized with more experienced Albanian and Estonian young experienced entrepreneurs during Summer 2018 and through using online social networks as interviewing tool. Quantitative data from survey was analyzed through Exploratory Factor Analysis technique in order to determine structure, seven constructs were determined, qualitative data was analyzed through manual thematic analysis, determining firstly from codes, and themes emerged.

In the second section literature in the field is review, methodology employed in the study corresponds to the third section, findings are presented in the fourth session, the paper concludes with discussion and conclusions in the fifth session.

\section{Literature Review}

\subsection{Facebook:Online Educational Social Network for International Entrepreneurial Learning}

Online social networks and especially Facebook through merging, web technology and social and interactive characteristics have drawn the attention of educators and students. Facebook became famous as for its "social" connectivity between end users. It is considered to be the principal online social network adopted from students for educational purposes (Roblyer et al, 2010). Scholars and public opinion are more and more concerned about how to transform entertaining and online interaction dimensions in learning incentives for young student Facebook end users, according to Shannon et al (2016) Facebook is used actively and increasingly from students for academic matters and they are more likely to commit in educational learning process in Facebook and to participate in educational activities in Facebook (Al-Ralmi et al., 2014). Young students in Facebook are not only consumers of knowledge but they can be producers of knowledge, this process is facilitated by the feature of instant sharing of information. Online social networks are not anymore just a way of getting in touch with others, knowledge is created and share (Johnston, Chen \& Hauman, 2013). Recent studies also show that young students value collaborative features of Facebook (Manasijevic et al., 2016), young students as learners are challenged with learning environment that they can use inside and outside formal higher education settings. As suggested by Johannessen (2018) Facebook is a relevant online social networking platform for sharing different types of content.

Entrepreneurship is a learning process as entrepreneurs and especially young entrepreneurs require information, skills and funding in order to start their business activities. International entrepreneurial learning is concerned with how young people 
construct the process of recognizing and acting opportunities with focus on organizing and managing the new venture (Rae, 2010). Entrepreneurial competence is by far a "hot topic" for society and academia (Young, 2014). According to Gupta and Bharadwaj (2013) business and universities education model for teaching and learning entrepreneurship should be reconsidered as this model goes beyond the higher education institution, focus should be put on the typology of learning process. Networking with others especially in online social networks is carried out because entrepreneurs depend on leverage that that they can get from networks especially in promoting and shaping new ideas(Porter et al.,2005). Entrepreneurial network must add value for the nascent entrepreneur (Foxton and Jones, 2011). Benson (2010) argues that young students who are new comers in the business field are keener to use online social networks for business purposes. In small transition economies such as Albania which coincide more with the Bazar-type economy suggested by Dana et al (2008) where the most important dimension of network is the relational dimension, online social networks such as Facebook can contribute to further widen entrepreneurial learning opportunities to an international dimension and with equal chances with other digital born peers.

In the learning process Facebook definition for some scholars would be more compatible with the construct of a learning tool for young students (Irwin et al., 2012), learning dimension of Facebook should go beyond pedagogical benefits for the students. Young students are native speakers of the "digital language" as there is a tendency to label them as digital natives or digital born, for them Facebook is more than just a tool in the learning process.

Recent studies from Buckenmeyer et al. (2016) have shown that social networks offer learning possibilities and different learning tools that facilitate their learning processes. Some Facebook features allows creating groups and groups timeline in to support the teaching and learning process of any curriculum subject through peer mentoring and tutoring support, it is as well a research tool where young students as learners can share, post content and discuss on different topics facilitated by instant communication features. With Facebook young students can be everywhere in every time, it is an engaging platform with an international outreach that can be used for personal and professional development. The sense of community through Facebook can be transferred from online to offline (Burt, 2010).

Online social networks can empower young students as digital natives to learn how to better use learning tools (Barr,2016). Facebook cannot be considered as a "single learning tool", it is a social educational learning network that includes different learning tools that combined with facilitation offered by networking structure. It offers to students "behind the scenes" opportunities of education that complement international entrepreneurial learning. While taking into consideration learning dimension of Facebook, it cannot be reduced just as a learning tool, Facebook as an online social educational network should be retained as a construct. Thus the theoretical construct that is more compatible to this study is social educational networking because it implies the use of online social networks for educational purposes (Davis, 2010). In entrepreneurship education networks can influence social processes which make mobilization easier (Greve, 1995) and an entrepreneur can gain different sources of information which help to develop the best business tactics (Chamlee-Wright, 2008).

Facebook remains the most popular online social network in the world. Some scholars as argue that the use of Facebook, Utomo(2015) argues that Facebook can used for entrepreneurial purposes even in collectivist societies. Facebook is not only a platform that it is easily accessible from every young student even in small transition economies such as Albania but as Room(2013) suggests Facebook and social media in general can help in promoting entrepreneurship. In collectivist contexts using online social networks for international entrepreneurial learning from young digitally born entrepreneurs requires a certain degree of readiness that goes beyond traditional awareness about entrepreneurship education and traditional entrepreneurial learning outcomes. It is not sufficient just to be an active user of Facebook, there are other dimensions that determine Facebook readiness for entrepreneurial purposes by young students within Facebook as an entrepreneurial learning environment.

\subsection{From Social Presence to Young Student Online Social Networking Readiness}

Readiness is generally described as willingness or preparedness of an individual or of an organization for a particular action. Furthermore e-readiness can be defined as with users with users competencies to trust on technology acceptance (Venkatesh et al., 2012), e-readiness tools help to cut time, cost and efforts (Beig et al., 2007). Social media readiness can be defined as the extent to which an individual or an organization is willing able and prepared to use social media for professional purposes or professional development.

There is a current definition that links social media readiness for entrepreneurship purposes especially focusing in young students.Levis and Clark (2006) elaborate a conceptual framework of youth entrepreneurship readiness taking into account the fact that young students in order to be entrepreneurs must be ready which is equivalent of possessing related knowledge and 
skills. Some scholars such as (Conduras et al, 2016) will focus as well in defining entrepreneurship readiness of young students as the ability of young people to explore various opportunities and the use of skills and capabilities to analyze the environment in order to channel their creative and productivity potential. Different factors may influence entrepreneurship readiness personal traits, family background, prior experience as well as social attachments and social networks (Macke and Markley, 2003).

Facebook is the most used online social network by young students, but yet even though much of research related to Facebook use for entrepreneurship has increased in the last years, there is not yet such a definition about entrepreneurial Facebook readiness for young students. It differs from other online social networks because it has an online and offline trend (Ross et al., 2009).

Thus it is important to clarify as well that most of the students are conscious that they have social presence in Facebook which it is traditionally composed by two elements intimacy (interpersonal) and mediated social presence (asynchronous versus synchronous) as defined by Short et al. (1976), social presence theory estimates that communication through media in general depend on the combination of both dimensions of intimacy and intermediacy. In terms of entrepreneurial learning young student should be able to get a leverage from their social presence in Facebook.

Several dimensions can create a puzzle of Facebook readiness for entrepreneurial learning for young as construct. Barsegian (2011) would underline that one of the main motivations of using Facebook in the learning process from young students are access to information and knowledge sharing. •ivkovic et al. (2016) conclude as well that one of the main motivations of using Facebook in the learning process is material/resource sharing, exchanging practical information, sharing experiences and learning from discussions not only with peers but the wider network. Information access and knowledge sharing as well as communication are the main component of student interaction that is generated in Facebook. Several studies confirm that social media and Facebook in particular may have a positive impact on student interaction (Junco et al., 2013, Al-Rahmi et al, 2015). On the other hand collaborative learning is characterized not just by student connections but as well as by student interactions. Students can build learning communities through Facebook by working collaboratively (Kabilan et al., 2010) especially through multiple collaboration not just with peers but with their wider online ties in different topics, discussion and creative entrepreneurial projects (Fewkes and McCabe, 2012) which are reinforced as well by creating, updating and maintaining group activities(Aydin,2012) especially through the Facebook group tool.

Multitasking in Facebook is characterized in engaging in several tasks while using Facebook in the entrepreneurial learning process, $\mathrm{Wu}(2015)$ estimates that young students although can have distraction in the learning process while using Facebook still can construct a kind of awareness through using social media notification tools for example that make them aware of selecting and processing learning-related things. Another facility that provides Facebook for young students in the entrepreneurial learning process as an online social network is online social networking monitoring that according to Kasper et al.(2011) consist in opportunity and event recognition, competitor analysis, trends and market research, influencer detection and product and innovation development. Young students just by using the right automated tools and content filters can quickly catch useful information and store knowledge, Facebook pages offer instant analytics to users (Lim et al., 2015) and to identify relevant learning outcomes for entrepreneurial purposes and learn about entrepreneurial opportunities(Lam,2012). Although Facebook can be misperceived as just an entertainment online social network for young student, entrepreneurial learning can still be an entertaining and useful process which is facilitating by constant changing sharing Facebook features which do not include only text but as well as multimedia, audio, videos, instant messaging, instant messaging for business, documents, live videos, animated videos and instant stories. Combining the dimensions of knowledge sharing, interaction and entertainment in the entrepreneurial learning process in Facebook, this online social networks offers to young students instant gratification through motivating them and responding to their entrepreneurial learning needs (Kink and Hess, 2008). Facebook readiness for entrepreneurial learning puzzle cannot be completed without exploring advantages and disadvantages of Facebook as an online social network for entrepreneurial learning among young students in a small open economy such as Albania.

\subsection{Opportunities And Challenges of Facebook for Young Student Entrepreneurial Learning in a Small Open Economy}

Facebook remains a fascinating online social network for young students even in small open economies such as Albania. It is has become a cliché to admit that young students are spending too much time in online social networks especially in Facebook (Gafni and Deri, 2012). On the other hand there is an aspect of the time construct which is real-time and instantaneity that offers Facebook as online social network can redefine time-efficiency construct of using Facebook for entrepreneurial learning purposes from young students. Speed and reactivity are two other characteristics that can be considered as benefit while using Facebook for entrepreneurial learning purposes (Salway et al.,2008). Young students can develop their own learning identity and 
advance in their autonomous learning process (Pasfield-Neofitou, 2011). Autonomy and independence is essential not just in the entrepreneurial learning process but as well for the entrepreneur which should be able to be independent but at the other hand networking is essential not just for co-creative projects but as well for individual projects, Facebook does not offer the possibility to connect with strong and weak ties but it enhances as well the possibility to build effective entrepreneurial teams(Khajeheian,2013). Reuber and Fischer estimate that online visibility and online social networks are an important source for the pursuit of international entrepreneurial opportunities. Another main advantage is overall is that Facebook is a cost-convenient especially for young students in small open economies (Wang et al., 2011).

Nevertheless, there are some barriers in using Facebook for entrepreneurial learning purposes by young students. As it was identified by a study performed with Albanian and Estonian students by Sula and Elenurm(2017) these online social networking barriers were identified: privacy and confidentiality problems, lack of social interaction and communication barriers with can be accelerated from some technical barriers that implies virtual communication, isolated learning process and cultural problems. Contextual change while using Facebook for entrepreneurial learning purposes implies as well problems connected with physical distance in the virtual context which excludes face-to-face interaction (Berge, 2013). Lack of time for learning and lack of appropriate tools can challenge as well entrepreneurial learning process in Facebook by young students (Al-Mashaqbeh, 2015).

In order to take advantage from opportunities and face challenges young students must rely on online networking competencies and support from appropriate expertise.

\subsection{Online Networking Competencies and Expertize and Implications for Online Entrepreneurial Learning Orientation}

Ala-Mutka(2011) considers that competencies are crucial for Facebook learning readiness. Within the framework of the current research most focus is put studying digital competencies and their influence in digital readiness in learning processes in general. Digital competencies refer to sets of knowledge, skills and attitudes relating to the effective use of digital technologies, they differ from from basic ICT skills. Different frameworks have been proposed for digital skills such as the framework developed by Van Dijk and Van Deursen(2014) which focuses on functional skills of citizens in order to access government, health and entertainment information online, whilst EshetAlklai and Chajut(2010) focused in the "thinking component" of the digital competencies that refers to those competencies that can enable people to process more diverse information and knowledge. Online networking competencies are more specific just that simple digital competencies. They combine the awareness to use online social networks and collaboration tools in online social social networks that can be provided by digital competencies frameworks and the network competencies that through different relationships build within online social networks can empower young student with entrepreneurial knowledge(Kamyabi and Devi, 2011). A pilot study conducted with Albanian and Estonian students during the academic year 2013-2014 by Sula and Elenurm(2014) determined a set of online networking competencies which include technical competencies, creative competencies, storytelling competencies, communication competencies, relationship building competencies, interpersonal competencies and monitoring competencies.

Online social networking such as Facebook represent a new opportunity to rely and facilitate mentoring and expertise support services for students in their entrepreneurial learning process. Online social networking mentorship can help to promote and share personal, professional and entrepreneurial development Shpigelman (2014). In the literature there are not yet specific contributions focusing on the leverage that young student can get from online social networking mentoring for entrepreneurial purposes even though guidance, feedback and the relationship build between mentor are important elements in leveraging online social mentoring in Facebook learning for entrepreneurial purposes.

Facebook remains an active actor in personal and professional development of young students especially in a small open economy such as Albania where Facebook can be considered as a window of learning opportunities for young students. This study explores how entrepreneurial learning in online Facebook can be developed in order to support readiness for young students in small transition economies and specifically in Albania.

Collaborative feature of online social networks facilitates learning process. Young student learners can take in the information that may change their type of knowledge that may be applied in new situations (Benson et al.,2010).

The approaches of action orientation focused entrepreneurial learning and collaborative context that offers online social networks can be integrated online social media readiness. Entrepreneurial learning orientation plays an important in young entrepreneurial learning processes in online social networks. As Elenurm et al (2007) suggest three types of orientation can be distinguished: an imitative entrepreneurial orientation that implies not just copying other's entrepreneurs ideas but as well a

86 Journal of E-Technology Volume 9 Number 3 August 2018 
readiness to monitor new trends and best practices in the markets, this kind of orientation limits the entrepreneur to be ready to share knowledge and opportunities in online social media settings. Individual entrepreneurial orientation would be suitablefor young students that operate in domestic markets where production differentiation is the main competitive advantage, this kind of orientation can be useful for long term research and development but when the entrepreneur is not involved with the ecosystem, there is a risk to be let out of the ecosystem. The co-creative orientation is the most evident reflection of the emerging online social and network economy and digital transformation especially in open innovation assumes the use of purposive flows of knowledge to accelerate internal innovation and simultaneously to expand markets for external use of innovation (Chesbrough et al., 2006). Co-creative orientation assumes competencies for applying knowledge received from other networking partners but also competencies for sharing entrepreneur's knowledge in order to create value for other network members.

Another aspect to be considered in online social network readiness and entrepreneurial learning orientation is the influence that the young student can create in online social network in the knowledge sharing processes. Online social networking influencer orientation is not concept that is explored previously in literature. Online social media influencer is explored traditionally as according to Forbes (2016) is and kind of status can shape the attitudes, actions and opinions of other people in their network. Although individual within the context of online social networks while interacting with other peers can take leadership positions and influence with their ideas and expertize, this will determine their entrepreneurial knowledge seeking opportunities within the context of online social networks. Young people particularly tend to be influenced by other peers who have a certain reputation and high status in entrepreneurial knowledge sharing processes (Xiang et al., 2015). Influencer orientation would require a more elevated and elaborated of knowledge and higher recognition or experience in the field.

Learning orientations for entrepreneurial purposes are not explored yet theoretically in the literature and especially in the context of small developing economies

\section{Methodology}

\subsection{Data Collection}

There is not a specific research focusing in readiness of young students in order to use Facebook as an entrepreneurial learning platform. Especially in the context of Albanian students or South Eastern European students more contributions are needed in the emerging field of online social networks and especially Facebook. Mixed methods approach was used in order to assure data triangulation in order to develop the concept of Facebook readiness.

Firstly aquestionnaire was distributed to Albanian students enrolled in Business Degree programs at the University "Aleksander Moisiu" Durres and University of Tirana in spring semester 2018, secondly comparative focus groups were realized in Tallinn and in Helsinki at the end of academic year 2018 during the course of Business in Virtual Networks at Estonian Business School in Tallinn and Helsinki. Semi-interviews were realized via online social networks with more 1212 experienced young entrepreneurs ( 8 from Albania and 4 from Estonia) which were former students or that were connected with the higher education institutions. Semi-structured interviews were realized during summer 2018 and the semi-structured interviews contained specific question about entrepreneurial learning orientations.

This study used an online questionnaire to explore how readiness in using Facebook as entrepreneurial learning platform for young students in Albania can be implemented. The survey was carried out during the spring semester 2018 with young students in Albania, more than 1000 questionnaires were sent having as respondents 489 students.

The survey contained 6 main sections : demographic, Facebook as an online learning network, , online networking advantages for learning, online networking disadvantages for learning, online networking competencies, online mentoring and expertize. In the demographic session were students were asked to specify their name, their age and their nationality. The other sessions contained 5 point Likert scale questions ranging from $1=$ Strongly Disagree to $5=$ Strongly Agree and the 5 remaining sessions contained in total 35 items retrieved from literature review and resumed in Table 1.

These items was retrieved from previous literature review, as the concept of Facebook readiness is not construct explored from literature there is a need of determining the structure of constructs and relevance of constructs composing Facebook readiness.

\subsection{Data analysis}

Journal of E-Technology Volume 9 Number 3 August 2018 


\begin{tabular}{|c|c|}
\hline Item & Rationale basis \\
\hline $\begin{array}{l}\text { Access to entrepreneurial information and knowledge } \\
\text { Parallel processing of information and multitasking } \\
\text { Multimedia and text diversity } \\
\text { Relevant entrepreneurial learning } \\
\text { Gratification and instant reward } \\
\text { Social monitoring of information } \\
\text { Updating group activities }\end{array}$ & $\begin{array}{l}\text { Facebook entrepreneurial learning network (Al-Rahmi 2015; } \\
\text { Aydin 2012; Barsegian 2011;Fewkes and McCabe 2012; Junco } \\
\text { et al. 2013; Kabilan et al. 2010; Kasper et al, 2011;Kink and } \\
\text { Hess 2008; Lam 2012; Lim et al. 2015Ross et al. 2009;Wu } \\
\text { 2015; -ivkovic et al. 2016) }\end{array}$ \\
\hline $\begin{array}{l}\text { Time efficiency } \\
\text { Communication flexibility } \\
\text { Speed and reactivity } \\
\text { Cost efficiency } \\
\text { International opportunities } \\
\text { Flexibility } \\
\text { Easiness in team building } \\
\text { Autonomy } \\
\text { Easiness in relying in support and help }\end{array}$ & $\begin{array}{l}\text { Advantages of entrepreneurial learning in online networks } \\
\text { (Khajeheian,2013;Pasfield-Neofitou 2011; Salway et al. 2008; } \\
\text { Wang et al., 2011; ) }\end{array}$ \\
\hline $\begin{array}{l}\text { Privacy concerns } \\
\text { Lack of trust } \\
\text { Lack of time } \\
\text { Physical distance } \\
\text { Isolated learning } \\
\text { Lack of interaction } \\
\text { Lack of collaboration } \\
\text { Communication problems } \\
\text { Technical problems } \\
\text { Lack of working culture } \\
\text { Lack of appropriate virtual tools }\end{array}$ & $\begin{array}{l}\text { Disadvantages of entrepreneurial learning in online net- } \\
\text { works (Al-Mashaqbeh,2015;Berge 2013; Sula and Elenurm } \\
\text { 2017) }\end{array}$ \\
\hline $\begin{array}{l}\text { Technical competencies } \\
\text { Creative competencies } \\
\text { Storytelling competencies } \\
\text { Collaborative competencies } \\
\text { Communication competencies } \\
\text { Relationship building competencies } \\
\text { Monitoring competencies } \\
\text { Interpersonal competencies }\end{array}$ & $\begin{array}{l}\text { Online networking competencies (Ala-Mutka 2011; } \\
\text { EshetAlklai and Chajut 2010; Kamyabi and Devi 2011; Sula } \\
\text { and Elenurm 2014; Van Dijk and Van Deursen 2014) }\end{array}$ \\
\hline $\begin{array}{l}\text { Expert/mentor offers entrepreneurial learning guidance online } \\
\text { Expert/mentor helps to enhance online entrepreneurial contacts } \\
\text { Expert/mentor makes learning process comfortable } \\
\text { Expert/mentor needs to have online experience } \\
\text { Feedback is immediate } \\
\text { Collaboration is more flexible }\end{array}$ & Online mentoring(Shpigelman (2014) \\
\hline
\end{tabular}

Table 1. Inventory of Likert scale Items included in the survey

Quantitative data analysis from survey was analyzed through employing Exploratory Factor Analysis (EFA) with the software SPSS to determine the underlying dimensional structure and validity of constructs through identifying the factors that will validate the constructs. After collected data was cleaned and it was subjected to normality and outer testing. EFA process 
provides a systemic factorial technique. Varimax Rotation was applied to determine the dimensionality of the measure. Items that failed to meet the loading requirement were removed for further analysis. From 42 items, only 33 items were retained for further analysis. Each of the factors identified meet the satisfactory level of internal consistency and adequacy.

Part of focus groups discussions were conducted in class during the course of Business in Virtual Networks at Estonian Business School in Tallinn and in Helsinki. The groups were composed by Finnish, Estonian and International Erasmus students. Albanian and international students in general are active users of Facebook, challenges of readiness in using online social networks for entrepreneurial learning were discussed in another cultural context where the course itself is focused in Business in Virtual Networks. Then in class discussion were led by the instructor having as principal questions focused on student how students can take leverage from the different entrepreneurial learning opportunities in Facebook compared to other online social networks and what kind of attitude do they undertake in their entrepreneurial learning in Facebook and in online social networks in general. The other part of the focus took place in Canvas where students posted different comments about their entrepreneurial learning experience in Facebook and in other online social networks in general. Focus groups usually are analyzed with grounded theory analysis. Data coding, data in chunked into small units and the researcher attaches a small code to each unit, codes are grouped in themes. Thematic analysis was used as well for semi-structured interviews.

\section{Results and Discussion}

\subsection{Results from Survey}

Kaiser-Meyer-Olkin (KMO) which measures the sampling adequacy is .82 which is above the recommended value of .5 , the Bartlet Test of Sphericity is also significant $(p<.05)$. Communalities indicate the degree with which each factor explains a percentage of the variance Varimax rotation which is with orthogonal nature was applied was applied to maximize the variance of squared loadings of each factor on all items in factor matrix. Factors were retained based on Pallant(2007) having as a general rule of acceptance of .3 and confirming that most of the items shared some common variance with other items. Items : gratification and instant reward, communication flexibility, flexibility, privacy, lack of trust, technical competencies, expert/mentor offers entrepreneurial learning guidance online, expert/mentor needs to have online experience did not meet the requirement and analysis was carried out without these elements. There are seven factors that can be retained from the analysis that explain $54 \%$ of the variance. These factors are labeled as: online networking learning competencies, Facebook learning environment, need for a friendly online learning community, operational benefits, opportunities for collaborative learning, support from online mentors and need to adapt to virtual learning reality.

In table 2 there are resumed the main findings from Exploratory Factor Analysis.

All the seven factors show a satisfactory reliability $\alpha>.7$.

Factor 1: Online networking competencies: is composed primarily by competency dimension related to the dimension of communicating, collaborating, building and maintaining relationships with others whilst it is important to maintain online social presence and profile through storytelling competencies. Creative competencies and monitoring which is essential in the online knowledge management process are relevant as well. Technical competencies somehow were not relevant, it can be assumed that somehow young students in Albania perceive them more as basic ICT skills or they consider themselves as friendly users of Facebook that is the most popular online social network in the country.

Factor 2: Facebook entrepreneurial learning environment: relevant knowledge exchange and processing and monitoring through the appropriate text and multimedia tools make Facebook an entrepreneurial learning environment, group feature allows to add the collaborative and learning community dimension.

Factor 3:Need for a friendly online learning community - the biggest challenges for the young student as entrepreneurial learner in Albania are physical distance, lack time, isolated learning and lack of interaction and collaboration that can be perceived as how young students perceive their entrepreneurial learning journey within the Facebook community where they can feel connected and disconnected at the same time.

Factor 4: Operational benefits - are mainly relation to operational features of Facebook as an online social network such as real time feedback, costless services, Facebook is everywhere and international opportunities can be everywhere. 


\begin{tabular}{|c|c|c|c|c|}
\hline $\begin{array}{c}\text { Number and name of } \\
\text { Factor }\end{array}$ & Item & Communalities & Loading & Alpha of Cronbach \\
\hline $\begin{array}{c}\mathbf{1} \\
\text { Online networking } \\
\text { learning competencies }\end{array}$ & $\begin{array}{l}\text { Creative competencies } \\
\text { Storytelling competencies } \\
\text { Collaborative competencies } \\
\text { Communication competencies } \\
\text { Relationship building competencies } \\
\text { Social monitoring competencies } \\
\text { Interpersonal competencies }\end{array}$ & $\begin{array}{l}.491 \\
.419 \\
.523 \\
.646 \\
.606 \\
.562 \\
.480\end{array}$ & $\begin{array}{l}.600 \\
.619 \\
.741 \\
.769 \\
.765 \\
.751 \\
.647\end{array}$ & .827 \\
\hline $\begin{array}{c}2 \\
\text { Facebook learning } \\
\text { environment }\end{array}$ & $\begin{array}{l}\text { Access to entrepreneurial information and } \\
\text { knowledge } \\
\text { Parallel processing of information and multitasking } \\
\text { Multimedia and text diversity } \\
\text { Relevant entrepreneurial learning } \\
\text { Social monitoring of information } \\
\text { Updating group activities }\end{array}$ & $\begin{array}{l}.485 \\
.449 \\
.475 \\
.461 \\
.422 \\
.500\end{array}$ & $\begin{array}{l}.559 \\
.628 \\
.673 \\
.677 \\
.573 \\
.672\end{array}$ & .798 \\
\hline $\begin{array}{c}3 \\
\text { Need for a friendly } \\
\text { online learning } \\
\text { community }\end{array}$ & $\begin{array}{l}\text { Lack of time } \\
\text { Physical distance } \\
\text { Isolated learning } \\
\text { Lack of interaction } \\
\text { Lack of collaboration }\end{array}$ & $\begin{array}{l}.417 \\
.633 \\
.646 \\
.551 \\
.533\end{array}$ & $\begin{array}{l}.562 \\
.829 \\
.808 \\
.682 \\
.634\end{array}$ & .784 \\
\hline $\begin{array}{c}4 \\
\text { Operational benefits }\end{array}$ & $\begin{array}{l}\text { Time efficiency } \\
\text { Speed and reactivity } \\
\text { Cost efficiency } \\
\text { International opportunities }\end{array}$ & $\begin{array}{l}.663 \\
.782 \\
.789 \\
.645\end{array}$ & $\begin{array}{l}.446 \\
.633 \\
.639 \\
.534\end{array}$ & .731 \\
\hline $\begin{array}{c}5 \\
\text { Opportunities for } \\
\text { collaborative learning }\end{array}$ & $\begin{array}{l}\text { Easiness in team building } \\
\text { Autonomy } \\
\text { Easiness in relying in support and help }\end{array}$ & $\begin{array}{l}.763 \\
.800 \\
.763\end{array}$ & $\begin{array}{l}.615 \\
.644 \\
.628\end{array}$ & .725 \\
\hline $\begin{array}{l}6 \\
\text { Support from online } \\
\text { mentors }\end{array}$ & $\begin{array}{l}\text { Expert/mentor helps to enhance online } \\
\text { entrepreneurial contacts } \\
\text { Expert/mentor makes learning process comfortable } \\
\text { Feedback is immediate } \\
\text { Collaboration is more flexible }\end{array}$ & $\begin{array}{l}.702 \\
.658 \\
.715 \\
.703\end{array}$ & $\begin{array}{l}.570 \\
.468 \\
.527 \\
.562\end{array}$ & .756 \\
\hline $\begin{array}{c}7 \\
\text { Need to adapt to } \\
\text { virtual learning reality }\end{array}$ & $\begin{array}{l}\text { Technical problems } \\
\text { Lack of working culture } \\
\text { Lack of appropriate virtual tools }\end{array}$ & $\begin{array}{l}.645 \\
.793 \\
.804\end{array}$ & $\begin{array}{l}.499 \\
.662 \\
.674\end{array}$ & .719 \\
\hline
\end{tabular}

Table 2. Exploratory Factor Analysis

Factor 5 Opportunities for Collaborative Learning - Raise from the fact that through Facebook team activities can be build and maintained more easily while relying in help and support and not being stuck between independence and interdependence in the learning process.

Factor 6 Support from online mentors- Online mentor can be considered as that "Facebook friend" that gives you immediate 
feedback and access to contacts through a collaborative friendly process within the Facebook learning environment. Online mentor is more a friend rather and "a know-everything guru".

Factor 7 Need to adapt to virtual learning reality - is challenge due to digital transformation of the learning process that needs the appropriate tools, learning culture and problem solving that maybe complicated with technical problem that young students do not face in the physical world.

Factors from Exploratory factor analysis can be grouped in terms of challenges and for developing Facebook readiness as online social network readiness for entrepreneurial learning. Challenges for developing online social networking readiness for learning emerge from: the need to adapt to the virtual learning reality followed by the need that the student has as at any stage of the entrepreneurial process for a friendly learning community. Benefits emerge from some operational benefits, the learning environment that provides Facebook in terms of learning as mentioned in Factor 2, as well as opportunities for collaborative learning, support from online mentors and online networking competencies.

\subsection{Results From Focus Groups And Semi-structured Interviews 4.2.1 Results From Focus Groups}

From the focus groups realized in different context from Albanian context such as Finnish and Estonian context with classes containing international Erasmus students in offline(in class setting) and online( through posting comments in Canvas) 8 codes with 2 main themes were identified : need to building an entrepreneurial learning culture in Facebook. Focus groups questions were not specifically focused in Facebook readiness but more in general to online social networks in general and Facebook came out as an answer in all the answers of students together with LinkedIn.

\begin{tabular}{|c|c|}
\hline $\begin{array}{l}\text { Theme 1: Need to build a learning entrepreneur- } \\
\text { ial culture in Facebook }\end{array}$ & $\begin{array}{l}\text { Theme 2: Support from online mentors is not just exper- } \\
\text { tise }\end{array}$ \\
\hline $\begin{array}{l}\text { Codes } \\
\text {-Over populated network } \\
\text {-Sharing platform mainly for entertainment pur- } \\
\text { pose } \\
\text {-People get stuck in the "friend" perspective of } \\
\text { Facebook } \\
\text {-Young people may are not focused or motivated } \\
\text { to look for opportunities in this network } \\
\text {-there is a lack of entrepreneurial ambition in } \\
\text { Facebook }\end{array}$ & $\begin{array}{l}\text { Codes } \\
\text {-Expertise sometimes does not have focus } \\
\text { - Young students maybe can be sometimes distracted } \\
\text { and not interested in expertise } \\
\text { - Young people even though in online social networks } \\
\text { can find many influencers, they should believe that they } \\
\text { can be themselves influencers. }\end{array}$ \\
\hline
\end{tabular}

Theme 1: Need to build a learning entrepreneurial culture in Facebook

Even though the focus group sessions were conducted in Tallinn and in Helsinki in a different cultural and social context from Albania, still the use of Facebook for entertainment purposes dominates compared to the use of Facebook for learning purposes from young people. "Absence of ambition", "absence of motivation" aspects as identified from coding processes show that students need to adapt to new online learning entrepreneurial learning culture and readiness can facilitate its building process within business school mindset while appropriating students with the adequate knowledge and skills.

Theme 2: Support from online mentors is not just expertize

The construct of expertize itself for many young students can be related to some kind of formal knowledge transfer, young students are more attracted from an immediate feedback that can be provided from instant interaction in online social network. Nevertheless the construct of influencer is related to online social networks but young generation is far from having idols and gurus, everyone in Facebook is a peer.

In focus groups most participants mentioned the importance of LinkedIn for their professional development because as a student pointed out: 
...LinkedIn is focuses more on like-minded people ambitious people that like to post about their work and achievements in online social networks...

In Estonian and in Finnish context and maybe in a more generalized Western European context, LinkedIn is an online social network that is wide spread among young whilst in the context of South Eastern Europe and more specifically in Albania LinkedIn is not very popular among young people. It is important to define as well what important to define how learning with peers can be achieved through LinkedIn as interaction process in this platform is different from Facebook.

\subsubsection{Results from Semi-Structured Interviews}

From thematic analysis of the 12 semi-structured interviews combined with some insights provided from Focus groups, three typologies of learning orientation can be determined:

Solo Entrepreneurial Learning Orientation- this kind of orientation corresponds more to the features of individual orientation as proposed by Elenurm et al. (2007). This kind of online entrepreneurial learning usually corresponds to the process of discovery of online social networks and in particular of Facebook as a platform that offers learning possibilities. As one participant from the semi-structured interviews would admit that at the beginning of his journey in online social networks he could not understand some simple features such as the appropriate use of an hashtag or how to appropriately search and benefit from different sources of knowledge content provided for example in the feature of Facebook groups.

...One was always feels the need to have assistance from the network in order to not get lost...

\section{Online Collaborative Learning Entrepreneurial Orientation}

As firstly it was suggested in focus groups the more involved you are in online social networks the more you are realized that you cannot be alone. Especially as one participant in the semi-structured interviews would admit the feature of Facebook groups is key for developing collaborative learning. In these groups everyone is keen to share knowledge and opportunities, one example mentioned was the group of Start Ups in Albania when even foreigner young students seek for knowledge and business opportunities in the country. One participant from Albania would share its own experience of failure of its Start Up project that did not limit him from sharing knowledge and its own experience in Facebook and in other online social networks. Collaboration in Facebook allowed to a participant from Albania to manage transition for marketing and sales from Facebook to other online social networks. A participant from Estonia admitted that collaboration generated more synergy for him and its business partner. As one participant from Albania would suggest collaboration is not just about to reach target audiences with a business to consumer approach, it is all about learning.

\section{Influencer Online Entrepreneurial Orientation}

As a participant from Albania who was influencer in the field of e-commerce would share its own experience and perspective him as influencer has had a moment of stagnation and he had to reinvent himself and its business model with he helps with an Indian influencer that he managed to encounter in a Facebook group about sales. Another participant from Albania admits that while changing the country the interaction with the audience changed, the role of influencer was questioned.

...Even if people are coming back constantly to me I don't feel an influencer...

A participant from Albania that manages the Facebook group about Start-ups in Albania does not feel as a guru in his field. An Estonian participant suggested that even at some point everyone influenced someone or has been influenced from someone, in entrepreneurial knowledge transfer you cannot be a guru.

In terms of readiness collaboration will always be the ultimate destination even for the young student or the young entrepreneur whom has a solo entrepreneurial orientation or an influencer entrepreneurial learning orientation.

\section{Discussion and Conclusion}

In the literature there are not yet contributions that studies that analyze Facebook perspective as an entrepreneurial learningnetwork for young people in small open economies in Southern Europe and more specifically in the case of Albania. In general even in a more generalized global context literature focuses in the educational potential of Facebook without consider ing the entrepreneurial learning potential. This study explored through quantitative and qualitative methods how Facebook

92 Journal of E-Technology Volume 9 Number 3 August 2018 
entrepreneurial learning readiness. Findings from statistical analysis using with data from survey performed in Albania showed that Facebook readiness is composed from seven constructs need for a friendly online learning community, operational benefits, opportunities for collaborative learning, support from online mentors and need to adapt to virtual learning reality. These constructs show that young students'readiness is beneficial for entrepreneurial learning but at the other hand young students need to adapt to challenges that arise from virtual learning environment in Facebook, digital transition is even more complicated in the case of small transition economies such as Albania. Focus groups performed in a different cultural and social context in Tallinn and in Helsinki showed that in order for student to be ready to use Facebook for entrepreneurial learning purposes more effort should be put in building a friendly culture of entrepreneurial learning Facebook, in the survey it was highlighted as well through the constructs of need of a friendly online learning community and need to adapt with virtual reality. In Albania LinkedIn is not a very well-know online social network among young students, a challenge for educators is to build capacities in online social networking tools to young people focusing in the different potential that every online social network for entrepreneurial learning purposes. Facebook readiness at one hand is a catalyst of entrepreneurial learning as it connects young students to a global accessible network but at other hand entrepreneurial learning in Facebook remains in a "taboo" in both cultural contexts, Facebook is beneficial when it comes to its instant and real-time collaborative features, young students still do not perceive clearly Facebook as a learning environment due to its informal and entertainment character. Based on the results of the semi-structured interviews collaborative orientation is key element for developing online entrepreneurial learning in the context of online social networks such as Facebook. The solo learner or the influencer learner will always tend to go towards collaboration orientation in order to establish their presence in such a network.

One recommendation for future research direction is that maybe more effort should be put in integrating Facebook and other online social network such as mentioned from young students LinkedIn as educational entrepreneurial in higher education curricula and entrepreneurial learning activities. In the process of entrepreneurial knowledge transfer in online social networks emphasis should be put on online networking competencies and support that can be provided from an online mentor that escapes the idea of the traditional expert but that at the same time is not an influencer, in the survey was showed the online mentor was more someone considered as a peer in the learning process that offers support rather that someone that is a knoweverything guru. Future research direction can be towards the kind of support that young students need in the entrepreneurial learning process and the kind of orientation that young students have in the entrepreneurial learning process in online social networks especially in small open economies such as Albania.

\section{References}

[1] Al-Mashaqbeh,I. F. (2015). Social media in practice: The challenges of using Facebook in higher education. Malaysian.Journal of Distance Education, 17 (2), 37-50.

[2] Al-Rahmi, W. M., Othman, M. S., \& Musa, M. A. (2014). Social media through collaborative learning in Malaysian higher education. Asian Social Science, 10 (8), 210-221.

[3] Al-Rahmi, W., Othman, M., Mi, Y. L. (2015). The Effect of Social Media on Researchers' Academic Performance through Collaborative Learning in Malaysian Higher Education. Mediterranean Journal of Social Sciences, 6, 193-203.

[4] Ala-Mutka, K. (2011). Mapping digital competence: Towards a conceptual understanding. Seville, Spain: Institute for Prospective Technological Studies (IPTS), European Commission, Joint Research Centre.

[5] Aydin, S. (2012). A review of research on Facebook as an educational environment. Educational Technology Research and Development, 60, 1093-1106.

[6] Barr, D. (2016). Students and ICT: An analysis of student reaction to the use of computer technology in language learning. IALLT Journal of Language Learning Technologies, 36 (2), 19-38.

[7] Barseghian, T. (2011). 50 reasons to invite Facebook into your classroom. Mind Shift: How we will learn.

[8] Barczyk, C. C., Duncan, D. G. (2013). Facebook in higher education courses: An analysis of students' attitudes, community of practice, and classroom community. International Business and Management, 6 (1), 1-11.

[9] Beig, L., Montazer, G.,Ghavamifar, A. (2007). Adoption a proper tool for e-readiness assessment in developing countries (case studies: Iran, Turkey and Malaysia). Journal of Knowledge Economy\& Knowledge Management, 2, 54-69.

[10] Benson, V., Filippaios, F. and Morgan, S. (2010) Online social networks: changing the face of business education and career planning, International Journal of eBusiness Management, 4 (1), 20-33. 
[11] Berge, Zane. (2013). Barriers to communication in distance education. Turkish Online Journal of Distance Education, 14, $374-388$

[12] Buckenmeyer, J., Barczyk, C., Hixon, E., Zamojski, H., Tomory, A. (2016). Technology's role inlearning at a commuter campus: The student perspective. Journal of Further and Higher Education, 40 (3), 412-431.

[13] Chesbrough, H.W., Crowther, A. K. (2006). Beyond high-tech: early adopters of Open Innovation in other industries. $R \& D$ Management, 36(3), 229-236.

[14] Coduras,A., Saiz-Alvarez, J.M, Ruiz, J. (2016) Measuring readiness for entrepreneurship: An information tool proposal. Journal of Innovation \& Knowledge, 1, 99-108.

[15] Dana, L.P., Etemad, H. and Wright, R.W. (2008) Toward a paradigm of symbiotic entrepreneurship, International Journal of Entrepreneurship and Small Business, 5 (2), 109-126.

[16] Fewkes, A. M., McCabe, M. (2012). Facebook: Learning tool or distraction? Journal of Digital Learning in Teacher Education, $28(3), 92-98$.

[18] Elenurm, T., Ennulo, J., Laar, J. (2007). Structures of Motivation and Entrepreneurial Orientation in Students as the Basis for Differentiated Approaches in Developing Human Resources for Future Business Initiatives. EBS Review, 23 (2), 50-61.

[19] Eshet-Alkalai, Y., \& Chajut, E. (2010). You can teach old dogs new tricks: The factors that affect changes over time in digital literacy. Journal of Information Technology Education, 9, 173-181.

[20] Forbes, C. (2016). Authentic friendship in the age of social media. Pacifica, 29(2), 161-174. https://doi.org/10.1177/ $1030570 \mathrm{X} 17715283$

[21] Foxton, F., and Jones, R. (2011), Social capital indicators review, Office for National Statistics, UK.

[22] Gafni, R. \& Deri, M. (2012). Costs and Benefits of Facebook for Undergraduate Students. Interdisciplinary Journal of Information, Knowledge, and Management, 7 (2012), p 45-61.

[23] Gephart, R. P. (2004), Qualitative research and the Academy of Management Journal, Academy of Management Journal, 47 (4), 454-462.

[24] Greve, A., (1995), Networks and entrepreneurship, an analysis of social relations, occupational background and use of contacts during the establishment process, Scand. J. Mgm. 11 (1), p 1-24.

[25] Gupta, N., and Bharadwaj, S. (2013). Agility in business school education through richness and reach: a conceptual model, Education+ Training, 55 (4/5), $p$ 370-384.

[26] Irwin, C., Ball, L., Desbrow, B.,Leveritt, M. (2012). Students' perceptions of using Facebook as an interactive learning resource at university.

[27] Johnston, K, Chen, M., Hauman, M. (2013), Use, Perception and Attitude of University Students towards Facebook and Twitter, Electronic Journal of Information Systems Evaluation, 16 (3), 200-210.

[28] Johanessen, M,R.(2018),Personal and Private: Using Framing and Network Theory to Examine the Diffusion of Opinion Articles on Facebook,Journal of E-technology, 9 (2),49-64.

[29] Joosten, T. (2012). Social media for educators: strategies and best practices. San Francisco: Jossey-Bass.

[30] Junco, R., Elavsky, C. M.,Heiberger, G. (2013). Putting twitter to the test: Assessing outcomes for student collaboration, engagement and success. British Journal of Educational Technology, 44 (2), 273-287.

[31] Kabilan, M. K., Ahmad, N., Abidin, M. J. Z. (2010). Facebook: An online environment for learning of English in institutions of higher education? Internet and Higher Education, 13, 179-187.

[32] Kamyabi, Y., Devi, S. (2011). An Empirical Investigation of Accounting Outsourcing in Iranian SMEs: Transaction Cost Economics and Resource-Based Views. International Journal of Business and Management, 6 (3), 81-94.

[33] Kasper, H., Kett, H. (2011). Social Media Monitoring-Tools. In T. Schwarz, ed.Leitfaden Online-Marketing. Das Wissen der Branche. Wagh"ausel: MarketingB"orse, 662-669

[34] Khajeheian, D. (2013). New Venture Creation in Social Media Platform; Towards a Framework for Media Entrepreneur ship. In Handbook of Social Media Management: Value Chain and Business Models in Changing Media Markets (p 125-142). 
Berlin Heidelberg: Springer Publishing Company.

[35] Kink, N., Hess, T. (2008). Search engines as substitutes for traditional information sources? An investigation of media choice. Information Society, 24 (1), 18-29.

[36] Lam, L. (2012). An innovative research on the usage of Facebook in the higher education context of Hong Kong. Electronic Journal of e-Learning, 10 (4), 378-386.

[37] Lim, W.L., Xavier, S.R. (2015) Opportunity Recognition Framework: Exploring the Technology Entrepreneurs. Am. J. Eco, 5, $105-111$.

[38] Macke, D and D. Markley (2003) Readiness for entrepreneurship: Tools for energizing entrepreneurship Central for Rural Entrepreneurship.

[39] Manasijevic, D., Zivkovic, D., Arsic, S., \&Milosevic, I. (2016). Exploring students' purposes of usage and educational usage of Facebook. Computers in Human Behavior, 60, 441-450.

[40] Pallant, A. (2007. Step-by-Step Guide to Data Analysis Using SPSS. Open University Press, Maidenhead.

[41] Pasfield-Neofitou, S. (2011). Online domains of language use: Second language learners' experiences of virtual community and foreignness. Language Learning \& Technology.

[42] Porter, K.A., Bunker Whittington, K.C., Powell, W.W. (2005), the institutional embeddedness of high-tech regions: relational foundations of the Boston biotechnology community in Breschi, S. and Malerba, F. (Eds.): Clusters, Networks, and Innovation, 261-296, Oxford University Press, Oxford, UK.

[43] Rae, D. (2010).Universities and enterprise education: responding to the challenges of the new era, Journal of Small Business and Enterprise Development. 17 (4), 591-606.

[44]Reuber, R., Fischer, E. (2011). International entrepreneurship in Internet-enabled markets. Journal of Business venturing, 26, 660-679.

[45] Roblyer, M. D., Doering, A. H. (2010). Integrating Educational Technology into Teaching. (5 ${ }^{\text {th }}$ Edition ed.) Boston, MA: Allyn \& Bacon.

[46] Roomi, M. A. (2013). Entrepreneurial capital, social values and Islamic traditions: Exploring the growth of women-owned enterprises in Pakistan. International Small Business Journal, 31 (2), 175-191.

[47] Ross, C., Orr, E. S., Sisic, M., Arseneault, J. M., Simmering, M. G., Orr, R. R. (2009). Personality and motivations associated with Facebook use. Computers in Human Behavior, 25 (2), 578-586.

[48] Sula, O. \&Elenurm, T.(2014). Challenges in developing online business networking competencies for Albanian and Estonian business students. 7th International Conference for Entrepreneurship, Innovation and Regional Development ICEI RD 2014, 5-6 June Nicosia, Cyprus. Ed. G.A.Papadopoulos, P. H. Ketidikis and A.Kofteros. 483-491

[49] Sula, O., Elenurm, T. (2017). Strategic Role of Social Networking and Personal Knowledge Management Competencies for Future Entrepreneurs. In: Benson, V.; Saridakis, G.; Tuninga, R. (Ed.). Analyzing the Strategic Role of Social Networking in Firm Growth and Productivity (248-266)

[50] Shannon G., Perrin A., Duggan M. ( 2016) Social media update 2016. Pew Research Center.

[51] Salaway, G., Caruso, J. B., Nelson, M. R. (2008). The ECAR study of undergraduate students and information technology 2008. Boulder, Colorado: EDUCAUSE Center for Applied Research.

[52] Short, J. A., Williams, E., Christie, B. (1976). The social psychology of telecommunications. New York, NY: John Wiley \& Sons.

[53] Shpigelman, C. (2014). Electronic mentoring and media. In D. L. DuBois, \& M. J. Karcher (Eds.),

[54] The handbook of youth mentoring (p 259-272) (2nd Ed.). Thousand Oaks, CA: Sage Publications.

[55] Statcounter (2018) Retrieved August 22, 2018 from http://gs.statcounter.com/social-media-stats/all/albania

[56] Statista. (2018) Retrieved August 22, 2018 from https://www.statista.com/statistics/264810/number-of-monthly-active-facebookusers-worldwide/

[57] Utomo, A., Reimondos, A., Utomo, I., Mcdonald, P., Hull, T. (2013). Digital Inequalities and Young Adults in Greater Jakarta: A Socio-Demographic Perspective. International Journal of Indonesian Studies, 1, 79-109. 
[58] Van Dijk, J. A. G. M., Van Deursen, A. J. A. M. (2014). Digital skills: Unlocking the information society. New York: Palgrave Macmillan.

[59] Venkatesh, V., Thong, J. Y. L., Xu, X. (2012). Consumer Acceptance and Use of Information Technology: Extending the Unified Theory of Acceptance and Use of Technology. MIS Quarterly, 36 (1), 157-178.

[60] Wang, Q., Woo, H. L., Quek, C. L., Yang, Y., \& Liu, M. (2011). Using the Facebook group as a learning management system: An exploratory study. British Journal of Educational Technology, 43 (2), 428-438.

[61] Welsh, D. H., Dragusin, M. (2013). The new generation of massive open online course (MOOCS) and entrepreneurship education. Small Business Institute Journal, 9 (1), 51.

[62] Wu, J. Y. (2015). University students' motivated attention and use of regulation strategies on social media. Computers \& Education, 89 (2015), 75-90

[63] Young, L. (2014), Enterprise for All. The relevance of enterprise in education. Department for Business, Innovation \& Skills and Prime Minister's Office. UK.

[64] Xiang Z, Magnini VP, FesenmaieSr DR (2015) Information technology and consumer behavior in travel and tourism: insights from travel planning using the internet, J Retail ConsumServ 22: 244-249.

[65] Zivkovic, D., Arsic, S., Milosevic, I.,Manasijevic, D. (2016). Exploring students 'purposes of usage and educational usage of Facebook. Computers in Human Behavior, 60, 441-450. 